\title{
The Dynamics of Firm Growth in Sub-Saharan Africa: Evidence from Ethiopian Manufacturing Sector 1996-2017
}

\author{
Kahsay Gerezihar Tsaedu ${ }^{1,2}$ (D) $\cdot$ Zhihong Chen $^{3}$ \\ Received: 11 September 2020 / Revised: 23 February 2021 / Accepted: 29 March 2021 / \\ Published online: 19 April 2021 \\ (C) The Author(s), under exclusive licence to Springer Science+Business Media, LLC, part of Springer Nature 2021
}

\begin{abstract}
Despite the pile of literature on firm growth dynamics, studies that use large census data have been greatly rare for developing countries mainly due to a paucity of data. This study, however, relies on a deep analysis of complete microdata of Ethiopian manufacturing firms over a very long enough period (22 years). Hence, this study adds to the ongoing debates on the firm growth dynamics, since we provided appealing econometric findings mainly emanating from the inclusive methodological approach implemented and the complete long period census data used, as it helped us to provide clear and consistent evidence against Gibrat's law. The results revealed that conditional on survival, younger and smaller firms grow faster. On the contrary, there is a pattern of negative persistence growth, where positive growth is followed by a negative growth after a year. Overall these findings show the presence of firms formed by subsistence-seeking entrepreneurs in the economy.
\end{abstract}

Keywords Sub-Saharan Africa manufacturing · Firm size · Firm growth · System GMM

JEL Classification C26 - D22 $\cdot \mathrm{L} 11 \cdot \mathrm{L} 25 \cdot \mathrm{L} 60 \cdot \mathrm{O} 55$

\section{Introduction}

After a couple of decades of scholarly inquiry, conventional literature on firm growth examining Gibrat's law had failed to provide conclusive evidence on whether the size of the firm is a determinant of its growth. While several studies show negative associations of firm size and firm growth (Coad 2007; Evans 1987a; Goddard et al. 2002; Hart and Oulton

Kahsay Gerezihar Tsaedu

gereziharkahsay@yahoo.com; kahsay.gerezihar@psi.gov.et

Zhihong Chen

zhihong.chen@uibe.edu.cn

1 Industrial Development Policy Study Center, Policy Studies Institute (PSI), 2479 Addis Ababa, Ethiopia

2 Present Address: University of International Business and Economics (UIBE), No.10 Huxin Dongjie, Chaoyang District, Beijing 100029, China

3 School of International Trade and Economics, University of International Business and Economics, Beijing 100029, China 
1996), many others found no such relation (Haltiwanger et al 2013) and some concluded medium-size firms have higher growth (Teal 2016).

Findings from developing countries indicate that though small firms grow faster, for the smallest starters the observed growth rates flatten quickly (Sleuwaegen and Goedhuys 2002; Bigsten and Gebreeyesus 2007; Nichter and Goldmark 2009; Arouri et al. 2018). Other studies have examined the so-called augmented Gibrat's law estimation, which mainly involves controlling other covariates on the regression of firm growth (Coad 2018). Although recent interests in the roles of firm age are growing, as some scholars included age as a relevant variable in regressions that investigate deviations in firm growth, less has been said about the roles of firm age on firm growth (Sutton 1997; Coad 2007, 2018). Though interests in appending the effects of age have increased, conclusions are still mixed; the methods implemented are different, and in general, the field is undeniably still far from reaching a maturity phase (Coad 2018; Coad et al. 2018).

With the increasing interest in studying firm growth, there are challenges as well. The empirical challenge in the literature is that the fundamental questions related to the patterns of firm growth have so far remained partly unanswered due to lack of appropriate datasets and disconnection between theory and empirical prediction (Champonnois 2008). Even though studies that used large census datasets on manufacturing are available for developed economies (for example Axtell 2001; Tang 2015; Coad et al. 2011, 2018), they are rare for developing ones due to a paucity of data. Despite this, few studies that have utilized complete microdata can be mentioned from developing countries (including Aydogan and Donduran 2019; Aydoğan 2020 among others) though they do not focus on manufacturing firms. This study, however, relies on the complete census-based microdata of Ethiopia's manufacturing sector spanning from 1996 to 2017.

The main inquiry of this study relates to the long-running debates on the determinants of firm growth, specifically the roles of firm size and age on the firm's growth dynamics. Within this scope, this study contributes to the literature by extending the previous works on firm growth dynamics in sub-Saharan Africa (SSA) in the following ways: first, earlier studies have typically used a single way estimation of firm growth, taking the complete weaker regression analysis or nonparametric estimation of the fully saturated regression as almost interchangeable. As little attention has been paid to methodological variations adopted by different studies, the central contribution of this study is to offer a multifaceted approach in investigating firm growth. Accordingly, this study employed both the parametric and nonparametric regression approaches to explore the coevolution of a firm's growth dynamics. In the nonparametric approach, we consider a fully saturated dummy variable regression with a one-way dummy and two-way models with a complete set of interactions.

Second, earlier studies, ${ }^{1}$ which have analyzed the relationship between firm size, age, and growth dynamics, are based on either a small section of industries (to overcome data handling difficulties) or employed incomplete datasets. Fortunately, the current study relies on a comprehensive census-based dataset for the entire population of Ethiopian manufacturing firms from 1996 to 2017. Third, our findings add to the ongoing debates on the firm growth dynamics, since we provided appealing econometric

\footnotetext{
1 There are few exceptions like Aydoğan (2020) utilizing Turkish microdata with full coverage though its focuses were not manufacturing firms, and Bigsten and Gebreeyesus (2007) using Ethiopian firm-level data from 1996 to 2003 .
} 
findings on the subject, which can stand as a new addition to the scanty literature of firm growth dynamics among firms in developing countries. In sum, our study offers partial, appealing findings mainly coming from the inclusive methodological advantage employed and the complete census-based dataset over a very long enough period (22 years), which helps us to provide clear and consistent evidence against Gibrat's law.

One of the key findings shows that average growth tends to be higher for smaller firms which signpost evidence against Gibrat's law. Although the results and the steepness of the nonlinear relationship vary among the specification employed, the study generally indicates that smaller and younger firms grow faster, and growth rates diminish with size and age. The nonparametric firm classifications that earlier studies argue are more robust to such concerns indicate that the inverse association between firm size and firm growth remained but not overwhelming when a firm's size is less than 20 workers and aged older than 40 years.

On both the nonparametric approach and the dynamic panel estimation, the study found that once firm size is controlled, the relationship between growth and age square (too old firms) disappeared and even reversed, which might be due to the inertia effect outweighing the learning effect for older Ethiopian firms. The strong negative effect of age and age squared on firm growth is perhaps the most striking result, suggesting in developing economies the new entrant and, actually, surviving firms are growing fast where growth rate does not continue as firms stay more years in the economy. Interestingly, this finding indicates the presence of lack of (natural) selection among Ethiopian manufacturing firms, which is in agreement with Akcigit et al. (2016) and Aydoğan (2020).

Labor productivity and capital intensity have consistently helped firms to grow, as indicated in the literature. This stylized fact is confirmed by our novel datasets. The ownership structure of a firm at the center of manufacturing firm policies has been mentioned as an important factor for firm growth. Surprisingly, our empirical evidence shows that privately owned firms have lower growth, in contradiction with recent empirical work (Amore et al. $2020^{2}$ ) that made a comparison between the family-owned business and non-family-owned business firm's performance during the Covid-19 pandemic.

Finally, the results showed that there is negative persistent growth of firms over time since growing firms are less likely to achieve similar growth in the subsequent period. This finding indicates a pattern of oscillating growth in the manufacturing sector. Above all, this paper has driven some stylized facts about the firm's growth dynamics and its evolution over time and some possible theoretical explanations for these facts.

The rest of the paper presents the basic benchmark framework, together with some "stylized facts" on firm growth dynamics of the incumbent literature germane to our analysis (Section 2), followed by a brief description of data and methods used (Section 3). Section 4 describes the nonparametric approaches, while Section 5 focuses on the main results obtained from cross-sectional estimations followed by the dynamic panel using advanced system-GMM estimations (Section 6). The last section concludes.

\footnotetext{
${ }^{2}$ Amore et al. (2020) concluded that family firms performed significantly above those of non-family firms during the Covid-19 pandemic and even the outperformance of family business during the pandemic is more pronounced among companies led by family CEOs.
} 


\section{Theoretical and Empirical Background}

From the studies conducted on the dynamics of firm growth, only a few have attempted to study Sub-Saharan African firms at the industry economy-wide level due mainly to the availability of data. Earlier conventional literature based on predominantly advanced economy data has documented that anticipated firm growth rates are independent of their size (Gibrat's law).

\subsection{Theory of Gibrat's Law}

Gibrat's law as demonstrated in Gibrat (1931), Simon and Bonini (1958), Sutton (1997), Coad (2009), Aydogan and Donduran (2019), and Dosi et al. (2019) can formally be stated as follows:

$$
X_{t}-X_{t-1}=\varepsilon_{t} X_{t-1}
$$

where $X_{t}$ is firm size measured by the number of engaged employees at time t, and $\varepsilon_{t}$ be a random variable representing an idiosyncratic, multiplicative growth shock.

If we take $\log$ arithms of both sides to approximate $\log \left(1+\varepsilon_{t}\right)$ by $\varepsilon_{t}$, we obtain ${ }^{3}$

$$
\log X_{t} \cong \log \left(X_{0}\right)+\varepsilon_{1}+\varepsilon_{2}+\ldots \ldots . . .+\varepsilon_{t}=\log \left(X_{0}\right)+\sum_{i}^{t} \varepsilon_{t}
$$

and as time increases, the term $\log \left(X_{0}\right)$ becomes insignificant, and the random term assumed to be independently distributed, randomized effect and the distribution of $\log X_{t}$ becomes well approximated by the normal distribution $\left(\varepsilon \sim\right.$ i.i.d. $\left.\left(\mu, \delta^{2}\right)+C L T \rightarrow L N\right)$.

$$
X_{t}=\left(1+\varepsilon_{t}\right) X_{t-1}
$$

This shows a firm's size at time t evolves as an accumulation of stochastic processes where growth stocks are explained by the idiosyncratic history of multiplicative shocks.

To test the correlations between firm growth and firm characteristics, following Evans (1987b), we can rewrite the Gibrat's model of firms growth equation throughout t-1 and t as:

$$
\ln \left(\mathrm{X}_{\mathrm{it}}\right)=\beta_{0}+\beta_{1} \ln \left(\mathrm{X}_{\mathrm{it}-1}\right)+\mathrm{u}_{\mathrm{it}}
$$

Subtracting $\ln \mathrm{X}_{\mathrm{it}-1}$ from both sides

$$
\text { Growth }=\ln \left(X_{i t}\right)-\ln \left(X_{i t-1}\right)=\beta_{0}+\beta \ln \left(X_{i t-1}\right)+u_{i t}
$$

where $\beta=\left(\beta_{1}-1\right)$

Gibrat's law suggests that:

- $\beta=1$ forever firm (i), which shows the law of proportionate effect, $\beta>1$ an evidence of a tendency towards monopoly, while $\beta<1$ shows small firms growing fast.

- $u_{i t}$ are random variables with zero mean. are random variables with zero mean.

\footnotetext{
${ }^{3}$ The logarithmic approximation is only justified if $\varepsilon_{t}$ is small enough (Sutton 1997, Coad 2009).
} 
Empirical findings of the prediction ofGibrat's law are rather mixed. ${ }^{4}$ Previous studies have found a tendency for large firms to grow faster. The mainstream studies using more recent datasets have found $\beta<1$ (see Hart and Prais 1956; Evans 1987b) implying small firms grow faster. Similarly, Teal (2016) found that medium-size firms have higher growth. However, significant empirical results show no relationship between firm size and its growth (Haltiwanger et al 2013). The lack of consensus on the literature is partly because of the lack of data and the methodological dissimilarities employed in the different studies.

\subsection{Like Milk or Wine? Theory of Age and Firm Growth}

The profit maximization theory of neoclassical models of perfect competition ignores the role of age on the process of firms' growth due to the assumption that firms tend to grow to the unique optimal size in the economy, in which the minimum efficient scale (MES) holds and, after that, the firm reaches its maximum stages and growth stops; equivalent agreements can be observed in settings characterized by imperfect competition.

Nowadays, on the contrary, attention to firm age is growing, as some scholars include age as an important independent variable in estimations of determinates of differences in firm performance (see for example Sutton 1997; Coad 2007). The theoretical predictions in the literature show age affects firm growth in terms of selection effects, learning-by-doing effects, and inertia effects.

Selection effects derive when selection forces gradually eliminate the relatively inefficient (the weakest) firm, and due to that the average productivity at the industry level of surviving firms increases, even if the productivity levels of individual firms do not change with age. The model of passive learning shows, in the prior stages of their existence, younger firms face more uncertainty about their type, so the update is stronger and hence growth rates are greater (Jovanovic 1982).

Learning effects arise when firms raise their productivity through learning from their experience. Empirical evidence shows age has definitely a role to play and younger firms may be disadvantaged in terms of efficiency, and thus, growth potentials from the accumulation of knowledge are lesser for younger firms due to that knowledge gained from experience is not easily transferable (see for example Arrow 1962; Geroski and Gugler 2004; Caves 1998).

Another channel through which age may affect firms' growth is allied to the theory of inertia effects. As firms get aged (gest older and older), they become increasingly inert and inflexible which pushes them to be less productive. That is, firms became inflexible to change as fast as the situation requires as their age increases and the willingness to grow fall offs with age (Hannan and Freeman 1984).

Empirical evidence from developing countries shows a negative association between growth and age. Some studies (like Das 1995 and Ayyagari et al. 2011) obtained that growth increases with age, and small but mature firms have the largest share of job creation. Recent studies from developed countries, like Haltiwanger et al. (2013), using a broad dataset found that young surviving firms grow more rapidly than their mature counterparts.

Although progress has been made in our knowledge, there are still many aspects remaining for refining our thoughts of how firm behavior changes as firms get older. One reason, it seems, is the lack of complete datasets in reporting firm-age dynamics (Headd

\footnotetext{
${ }^{4}$ See Sutton (1997) for review of the evolution of the literature.
} 
and Kirchhoff 2009). In our case, however, age is directly reported for all firms. Thus, this paper complements the literature by studying changes in the growth of manufacturing firms with the age spectrum.

\section{Data, Variable, and Descriptive Analysis}

\subsection{Data and Variable Description}

In Ethiopia, comprehensive firm-level data collection from all establishments has been compiled annually since 1996. In this paper, the large and medium manufacturing firm's survey of Ethiopia conducted by a government institution called the Central Statistical Agency ( CSA $^{5}$ hereafter) is employed for the successful accomplishment of this study. This annual census data is a survey of entire manufacturing establishments employing 10 or more workers active at some point during the period from 1996 to 2017. The panel contains both continuous incumbent firms and firms that entered or exited during the survey period. These are considered the large- and medium-sized manufacturing industries (LMMIS) in the Ethiopian economy. This 22-year unbalanced panel covers 32,978 observations. While the survey aims to include only establishments that engaged 10 or more workers, few firms reported less than 10 workers. This microdata has been employed in numerous recent papers to study various aspects of firm performance in the economy (Bigsten and Gebreeyesus 2007; Söderbom 2012; Oqubay 2019 among others).

Table 1 presents the size distribution of employment in terms of different sizes, ages, and status categories. In this study, firm's age is defined as the difference between years of establishment and the survey year, while the year of establishment is the reported year of commencement in the CSA database or, wherever that is missing, to the first year that indicates positive employment. Note, however, that positive age of the new entrants is quite possible due to the survey being truncated into firms engaged 10 or more workers and hence positive-aged informal firms may grow up and join the large- and mediumsize firms category. In case of missing years of commencement (621 (2\%) reported with the missing birth year), the first year of appearance (being included in the survey) is assumed as a year of establishment. For those units where this coincides with the first year of the database, and a year of establishment is missing, age is not defined. Note that in only 144 (less than $0.44 \%$ ) firms age is not defined. Evidence in the existing literature (like Coad et al. 2014 and Haltiwanger et al. 2013) shows younger firms grow fast.

Table 1 provides the important fact that manufacturing firms in Ethiopia are predominantly small and young, and the average number of workers engaged in more than proportionally increased with size. Above all exited and new entrants are pretty smaller than the incumbent firms, which might appear the potential reason why manufacturing firms enormously exited from the economy throughout the period.

Table 2 describes the basic variables and how the given dataset is constructed. Firm growth is calculated as the differences in the logarithm of employment in two consecutive periods.

$$
\text { Growth rate }=\ln \left(S I Z E_{i t}\right)-\ln \left(S I Z E_{i t-1}\right)
$$

\footnotetext{
5 Additional details about the data, and related reports, can be found at the official website of CSA, http:// www.csa.gov.et.
} 
Table 1 Summary statistics

\begin{tabular}{lcccccccc}
\hline Size & $N$ & Mean & sd & Min & p25 & p50 & p75 & Max \\
\hline \multicolumn{7}{l}{ Panel A Employment distribution by Size group } \\
0-19 & 12,335 & 12.56 & 4.27 & 0 & 10.17 & 13 & 16 & 19.83 \\
$20-49$ & 9999 & 30.22 & 8.24 & 20 & 23 & 28 & 36 & 49.83 \\
50-99 & 4047 & 69.46 & 14.20 & 50 & 57 & 67 & 80.83 & 99.83 \\
100-249 & 3306 & 157.31 & 42.25 & 100 & 120 & 150 & 189 & 249.67 \\
250-499 & 1682 & 350.66 & 72.04 & 250 & 287 & 337 & 408.83 & 499.75 \\
500+ & 1450 & 1219.15 & 1231.99 & 500 & 624 & 819 & 1243 & 12,170 \\
Total & 32,819 & 110.17 & 361.62 & 0 & 14.83 & 26 & 70 & 12,170 \\
Panel B Employment distribution by Age group & & & & & \\
0-5 & 10,784 & 57.50 & 201.70 & 0 & 13 & 21 & 43 & 9960.67 \\
6-10 & 8866 & 72.02 & 228.36 & 0 & 14 & 25 & 54 & $10,439.17$ \\
11-20 & 7223 & 104.34 & 316.78 & 0 & 15 & 27.17 & 72 & 7320.67 \\
21-40 & 4358 & 198.09 & 519.82 & 0 & 18 & 48 & 189 & $12,170.00$ \\
40+ & 1588 & 466.16 & 873.43 & 0 & 52.33 & 188.83 & 524.75 & $10,699.67$ \\
Total & 32,819 & 110.17 & 361.62 & 0 & 14.83 & 26 & 70 & $12,170.00$ \\
Panel C Share of employment distribution of entrant exited and incumbent firms & & 12 \\
Exit & 9160 & 77.44 & 317.23 & 0 & 12 & 21 & 46 & $10,699.67$ \\
Entrant & 11,827 & 79.03 & 283.45 & 0 & 13 & 21 & 48.17 & $11,484.67$ \\
Incumbent & 20,992 & 127.72 & 397.91 & 0 & 16 & 30 & 85.08 & $12,170.00$ \\
All firms & 32,819 & 110.17 & 361.62 & 0 & 14.83 & 26 & 70 & $12,170.00$ \\
\hline
\end{tabular}

Source: author's calculation based on CSA raw data

\subsection{Firm Dynamics}

\subsubsection{Age Distribution of Firms}

Figure 1 depicts the nonparametric estimates of the skewness of employment size distribution (panel a) and sales value (panel b) for the 22-year pooled surveys (solid line) and different age groups. The distribution of a firm's size for the entire sample (solid line) is right-skewed and skewness diminishes with age, which indicates that age has a significant role in shaping the evolution of firm size and growth. As firms age, the mode decreases, the right tail becomes longer and the left tail got thinner, and the degree of skewness tends to diminish with age.

To support the analysis, we looked at FSD measured by the log of sales value over time. Similarly, the skewness panel (b) diminishes as the cohort ages. The hypothesis of equality of the FSD is strongly rejected for any two adjacent age cohorts. Our results appear to be in line with the evidence of Cabral and Mata (2003) from Portuguese and Angelini and Generale (2008) from Italian manufacturing firms that engaged more than ten employees.

\subsubsection{Entry and Exit Margins by Firm Age and Size}

The left panel of Fig. 2 illustrates the relationship between the exit rate and firm age. In line with Clementi and Palazzo (2016), we have found a high exit rate for younger firms. 


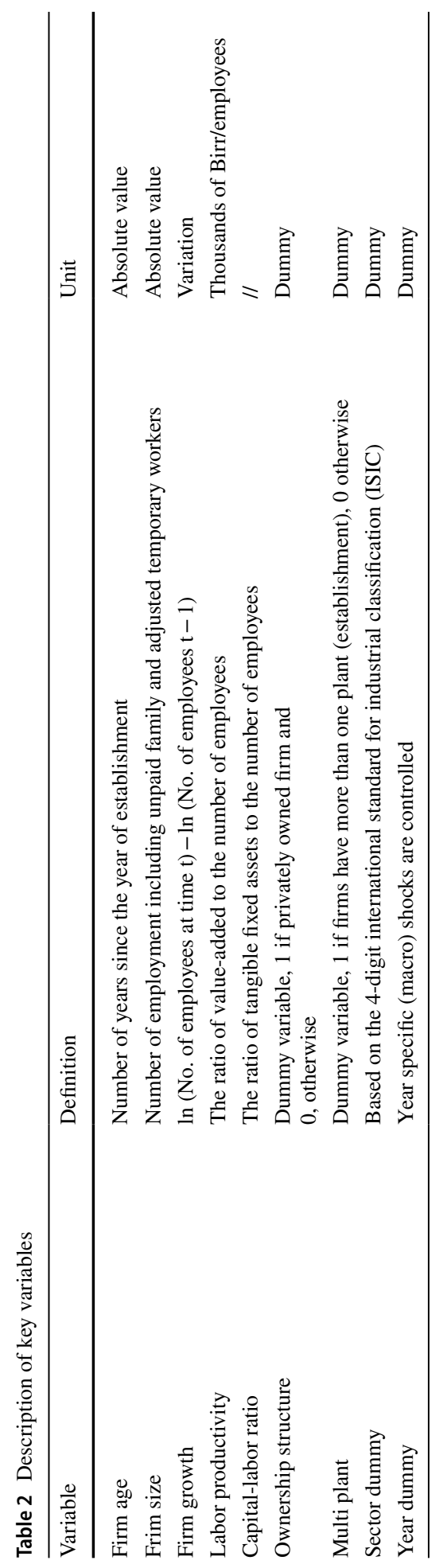



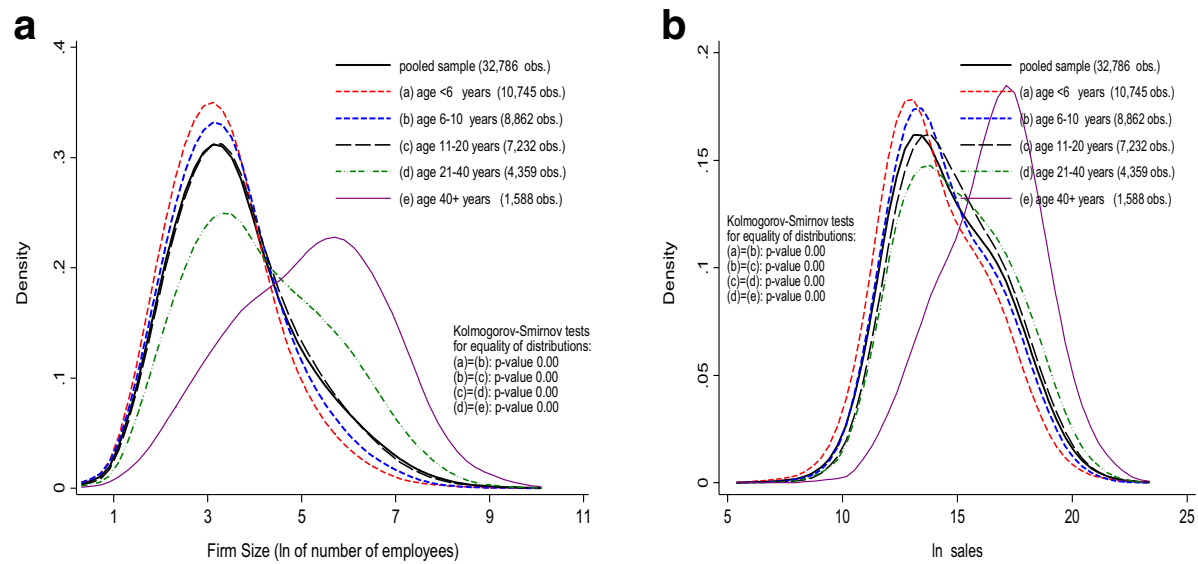

Fig. 1 The role of age on the firm size distribution. a FSD (log of employment). b FSD (log of sales value in Birr). Source: authors' computation using CSA dataset. Note: the figures show the kernel density estimates of FSD for the 22-year pooled survey (1996-2017) by age. The curves are estimated using a normal kernel density smoother with a bandwidth of 0.7

The average exit rate declines convexly as it converges to a constant steady state after the age of 20. Our finding suggests that the selection process of the passive learning model is also borne out in Ethiopian manufacturing.

Similarly, the right panel of Fig. 2 displays younger firms are now unambiguously more likely to have higher exit rates than their counterparts while the smallest firms were much more likely not to be traced and therefore have much higher rates of exit, and exit rate sharply declines with size.

\subsubsection{Up or Out Dynamics of Firms by Sector}

Turning to a sector-wise study, firm size varies considerably across sectors. Food and Beverage accounts for the largest share of employment (29\%) followed by textile and other non-metal industries. In terms of the number of firms, both the food and beverage, nonmetal industry, and furniture industry account for around $60 \%$ of manufacturing firms. Textile, wearing and apparel, and motor vehicle are more labor-intensive (accounts for higher
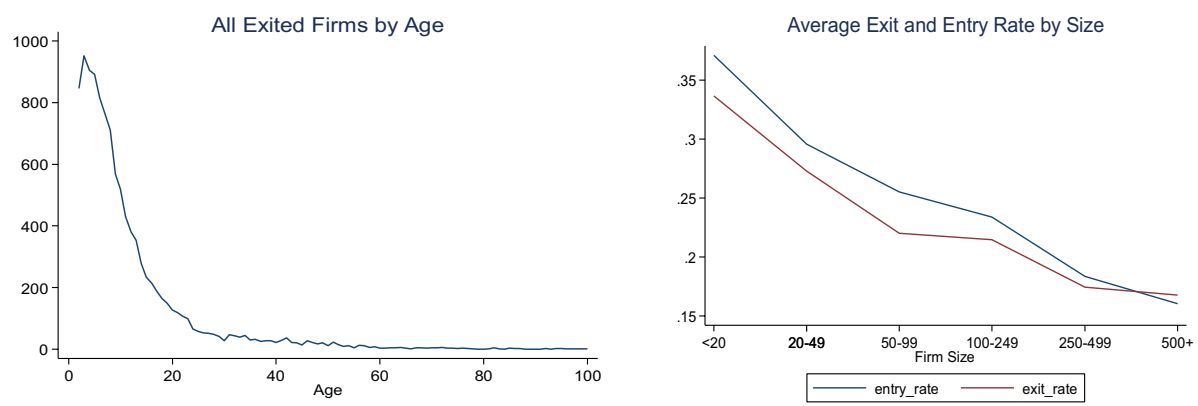

Fig. 2 The exit and entry rate by age and size. Source: author calculations from the Central Statistics Agency (CSA) dataset 


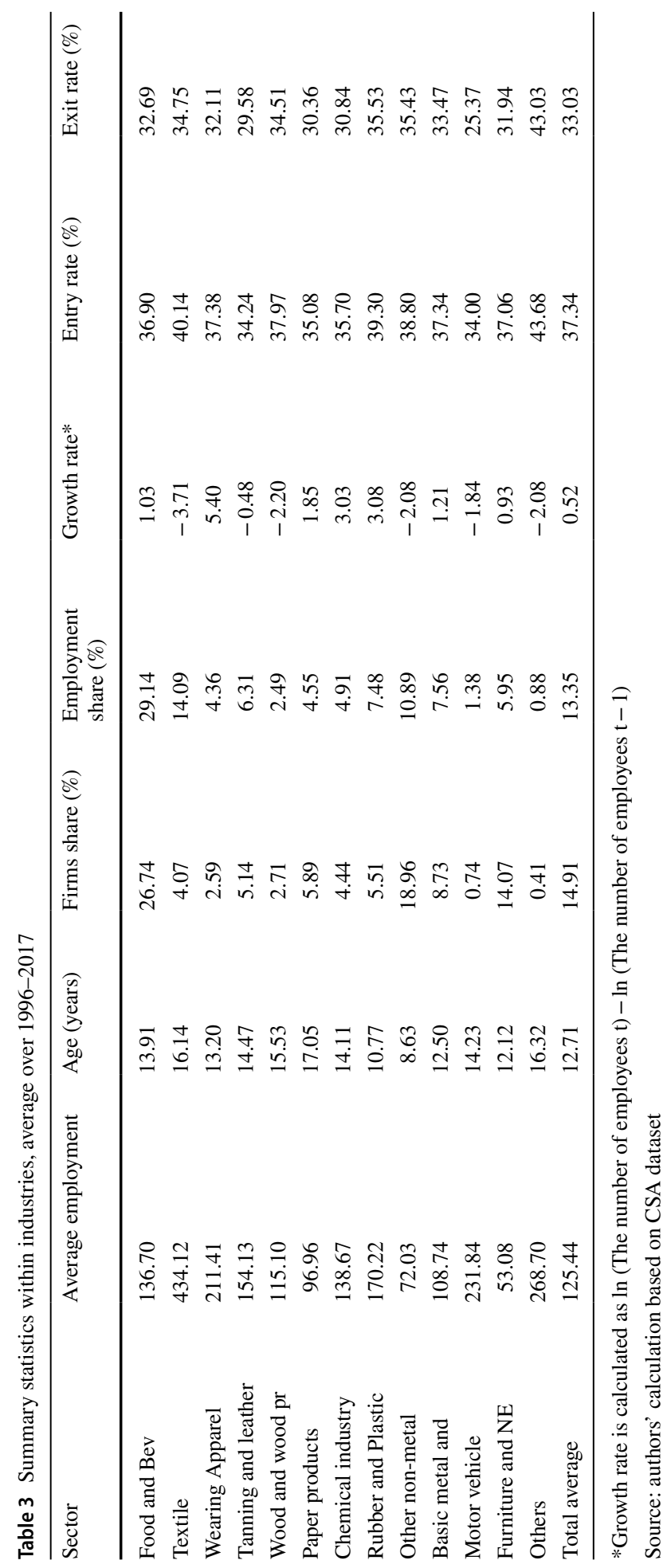




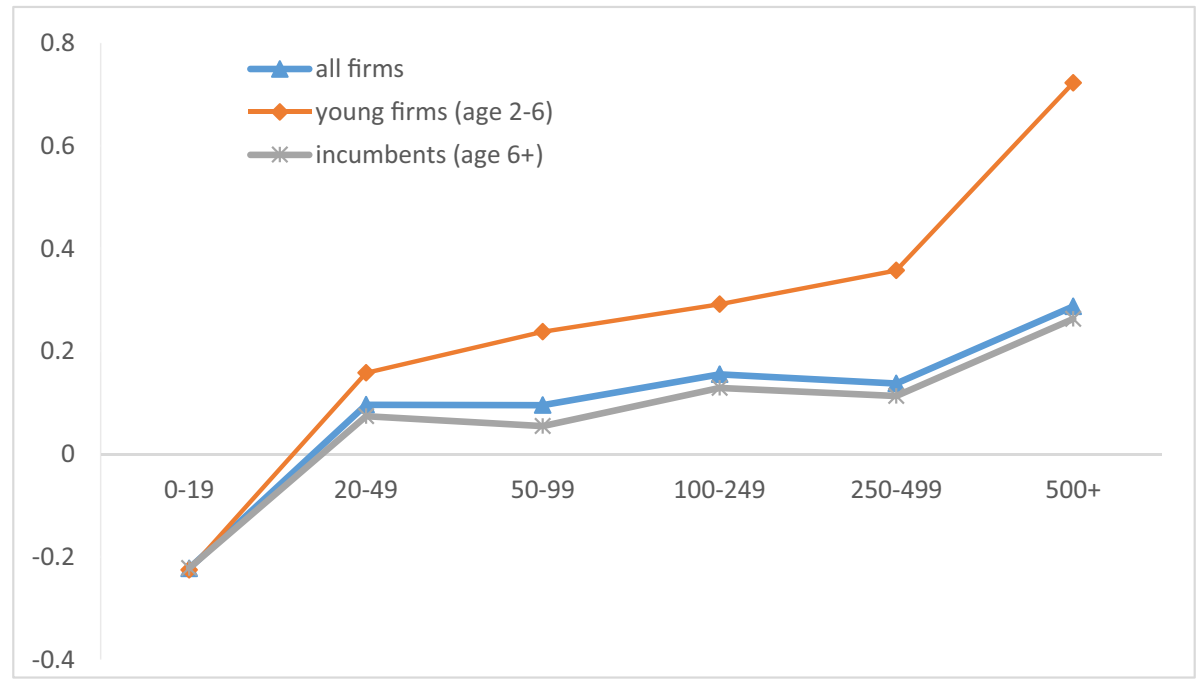

Fig. 3 The growth rates of young versus incumbents surviving firms by size. Source: authors' calculation based on CSA dataset

labor per firm). Wearing and apparel, rubber, and plastic, and the chemical sector recorded a higher growth rate than those in other sectors. Textiles and Wood were observed to be the two worst performing sectors in terms of growth. Other non-metal sectors are relatively younger firms, accounting for $18 \%$ of the total firms yet experiencing negative growth. Table 3 also demonstrates the entry and exit rates of firms by sector. An important point to highlight is that entry rates and exit rates are significantly high across all sectors.

\section{The Relationship of Firm Age, Firm Size, and Employment Growth}

In this section, the relationship between the growth dynamics of a firm and its components, firm size, and firm age is analyzed and presented. Here the study specifically adopts the nonparametric approach to quantify these relationships. Hence, considering the fully saturated model as demonstrated in recent literature (Haltiwanger et al. 2013; Geurts and Van Biesebroeck 2016), firm's growth at the firm level on different firm size and age classes, and by firm size and age interacted together are regressed.

Unlike most studies, the evidence indicates that a firm's growth between all firms that have survived in two consecutive periods is smoothly continued with size, and turns up substantially for the largest firms with more than 249 employees. Firms with up to 20 employees experienced negative average net employment growth during the survey period, while firms in the range above 20 employees experienced positive employment growth.

It is informative, however, to separately demonstrate the size-growth relationship in different age categories especially for younger firms of at most 6 years old, and that of relatively matured ones. The bottom line in Fig. 3 displays the lowest rate of growth for incumbent firms regardless of firm size.

In contrast, the growth rate for younger firms is higher and monotonically increases with size, which suggests once we control size young firms grow faster and the growth rate of 
a

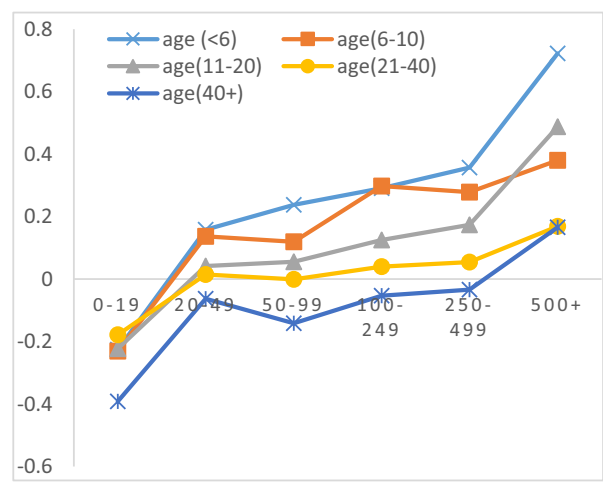

b

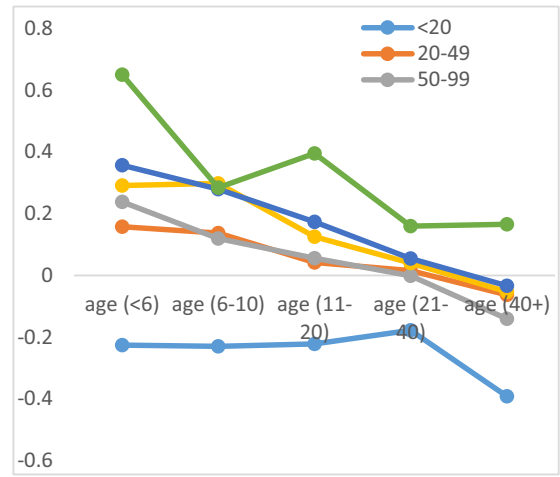

Fig. 4 Growth rates by age and size categories of surviving firms. a Growth size pattern by age group. b Growth-age patterns by size group. Source: authors' calculation based on CSA dataset. Note: annual averages over the 1996-2017 period

younger firms is higher for large-sized firms. Such a relationship between a firm's age and growth has often been documented in the literature.

Although the higher growth rate of younger firms is consistent with the commonly observed finding in the literature, the patterns of growth and size described in Fig. 3 have some contradictions which need better investigation and justification in the coming sections of this paper. To mention some, the negative growth rate of all firms irrespective of age in the lower size firms $(<20$ employees) is surprisingly uncommon. Finally the observed positive relationship between growth and size among young firms, however, is replicated in all categories of firms.

To demonstrate the post-entry growth of firms in a more robust way, we went to illustrate the patterns of firm growth in different sizes and age categories. Figure 4 plots the average employment growth of firms that survived from period $t-1$ to $t$ within each agesize class.

As can be seen from Fig. 4 in panel a, we learn there are relatively higher growth rates for younger firms of different sizes. We have also observed that older firms (firms with age above 40) registered negative growth rates in all size categories except for firms that have more than 500 workers. The relationship between age and growth indicates that young surviving firms in all size categories experience relatively higher growth rates and the growth rate diminishes with age keeping size constant, which is consistent with the prediction of the passive learning model. Growth rates were found to be higher for large firms and negative for too young firms but relatively smooth in the middle.

The positive association between firm growth and firm size is most pronounced for firms with a size above 250 employees and less than 40 years old.

Panel $b$ of Fig. 4 shows the pattern of firm's growth against age with different curves for each size class, highlighting shrinking growth rates to approximately zero for incumbents that hold for all firm sizes above 20 employees. The pattern indicates that growth rates diminish in the current age for firms of the same size group. Though larger firms grow more rapidly on average, the growth rate monotonically diminishes with age. Surprisingly, irrespective of their age, small firms ( $<20$ employees) have negative growth. In summary, 
our result suggests that younger firms grow faster, growth rates continue to decline with age, and ultimately converge to zero in all size classes except for the two side extreme size groups.

To more strongly validate our analysis, we further empirically investigate and test the link among firm size, age, and other covariates with growth in the following econometric analysis section.

\section{The Econometric Framework and Results}

\subsection{The Econometric Model}

To empirically test the relationship between firm growth and firm attributes, adopting Evans' (1987b) more advanced econometric method, the growth model is specified as follows:

$$
\ln X_{i t}=\beta_{i 0}+\beta \ln X_{i t-1}+u_{i}
$$

Subtracting $\ln X_{i t-1}$ from both sides gives

$$
\ln X_{i t}-\ln X_{i t-1}=\beta_{i 0}+(\beta-1) \ln X_{i t-1}+u_{i t}
$$

Here, $i$ refers to the firm and $t$ denotes time, while $X$ refers to the size of a firm, and $u_{i t}$ is the stochastic error term. The coefficient $\beta_{1}=(\beta-1)=1$ is the parameter of interest and if $\beta_{1}$ is equal to one, it can be evidence that Gibrat's law holds. While $\beta_{1}<1$ indicates smaller firms grow rapidly, which is evidence against Gibrat's law, $\beta_{1}>1$ shows size diverges from its mean, which can be evidence that large firms grow faster and there is a tendency of market concentration and monopoly. This paper is mainly focused on the effect of firm size and age on the growth of the firm.

Following previous works in the literature, the second-order logarithmic expansion of the above equation can be written as follows;

$$
\begin{aligned}
\text { growth }_{i, t}= & \alpha+\beta_{1} \ln X_{i t-1}+\beta_{2}\left(\ln X_{i t-1}\right)^{2}+\beta_{3} \ln A_{i t-1}+ \\
& \beta_{4}\left(\ln A_{i t-1}\right)^{2}+\beta_{5}\left(\ln X_{i t-1}\right)\left(\ln A_{i t-1}\right)+\delta^{\prime} Z+u_{i t}
\end{aligned}
$$

The squared values of size and age help to capture the possibility of non-linear relationships. Then, we regressed two growth equations separately using ordinary list square (OLS): regression for surviving incumbent firms only and for all firms including exiting firms in their pre-exit period. The last regression helps to eliminate the bias that comes from ignoring exited firms in the estimations of firm growth.

\subsection{Regression Results}

The analysis in this section aims to examine whether firm age and firm size can have a meaningful role in firm growth. It is a fact that size and age may not be the only explanatory variables that determine the firm's growth. Earlier literature shows multi-establishment (dummy variables of firms with more than one establishment), ownership structure 


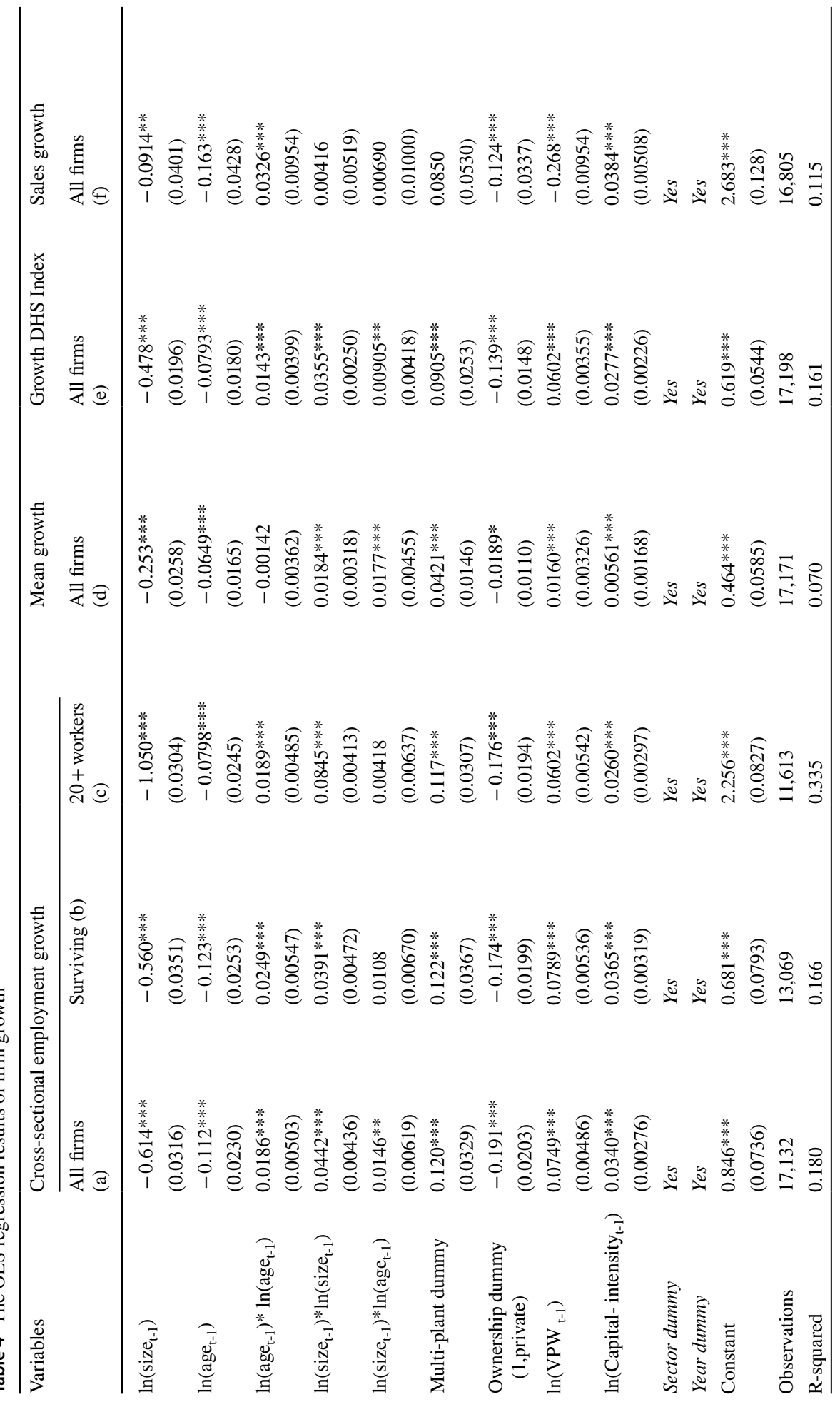




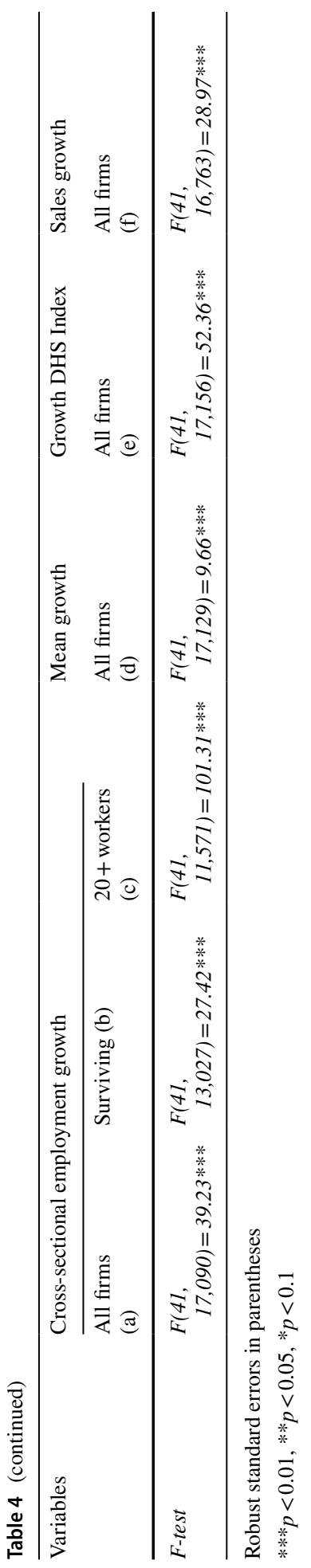


(private or SOE), capital intensity, labor productivity, and sector and year dummy are among the few factors that determine a firm's growth.

Table 4 presents the results of six different estimations estimated from all the possible specified models. Finally, sales growth is estimated as an alternative measure of growth in the last column (robustness check). Table 4 illustrates size has a negative and statistically significant correlation with growth in all the alternative specification of the growth model, while the squared term of size has a positive and significant sign in all except when growth is measured in terms of sales value, suggesting that the relationship between growth and size is convex. This indicates that the size of a firm affects its growth negatively, but the negative effect reduces with size and finally turns up. Hence, our data provide evidence against Gibrat's law of proportionate effect. It also corroborates the findings of Bigsten and Gebreeyesus (2007) for Ethiopian manufacturing firms from 1996 to 2003.

The F-test for the null hypothesis of all explanatory variables are jointly zero is significantly rejected at a one percent level in all alternative models. Although there is a slight difference in magnitude, the sign and level of significance of estimated coefficients in the regressions for all firms in their pre-exit period in column (a) and the only surviving firms in column (b) are quite similar in all alternative specifications, suggesting that the inverse association among firm growth and firm size should not be the result of sample censoring or model specification at all.

The inverse association between firm growth and firm size is also robust across the different firm size categories; however, $a$ larger negative value (greater than one in absolute value) is observed when we censored and exclude the firms in size category less than 20 employees (specification c). This surprisingly contradicts the conclusions of previous findings by Bigsten and Gebreeyesus (2007) which claims that the inverse size-growth association is not because of the elimination of firms that have fewer than 10 employees. It is also in line with the evidence observed in section four of the nonparametric estimation that irrespective of age and size the growth rate of firms with less than 20 workers is exceptionally different.

Put differently, the inverse relationship might hold but the magnitude is quite large in absolute value in the censored data, which suggests conclusions might be sensitive to size cutoff.

To address the statistical concern of the phenomenon of regression to the mean arising from transitory fluctuations in size or transitory measurement errors, following Haltiwanger et al. (2013), we provided a separate estimation of the mean growth model and results are reported in column $d$ of Table 4 . The size coefficient is still negative and statistically significant, suggesting that our finding is not because of the fluctuations or measurement errors in size. Hence, growth rates are estimated as discrete-time employment growth as compared to the average of employment in year $t-1$ and year $t$ in (column e). The coefficient for size is similar but the standard errors are slightly lower than the other alternative specifications.

Column (f) of Table 4 displays the estimated results using sales volume as a measure of firm size. Similarly, the results of the sales growth model were found to be broadly consistent with the other estimations. The size coefficient is still negative and significant, while the coefficient of the square term is positive but not significant which provides analogous evidence of smaller firms growing fast.

A negative association between firm age and firm growth is sensed in all specifications, which indicates clear and consistent evidence that younger firms grow faster. Similarly, the positive and highly significant effect observed in the secure term of age implies that the correlation between firm growth and firm age is convex. Thus, age has a non-symmetrical 
effect on growth, depending on the fact that the firm is either in a positive (older firms) or a negative (younger firms) path. This suggests that the age of a firm and growth rates are negatively associated, though it diminishes with age. Though the interaction term is positive in all the alternative growth models, it is only significant in some.

Labor productivity was found to be positive and significantly associated with firm growth in all models. This might be evidence for the associations of productivity and firm growth, suggesting productive firms grow faster, which is in line with the predictions of the passive learning model (Jovanovic 1982). However, labor productivity is negative and significantly correlated with the firm's growth when growth is measured in terms of logarithmic change in sales volume. Capital intensity is also estimated with a positive and significant coefficient, indicating firms with greater capital-labor ratios have better growth rates than their counterparts.

The multi-plant dummy implies a positive and highly significant association with growth in all models, implying that firms with more than one establishment (plant) grow faster than standalone, possibly indicating a diversified experience that comes from different branches may have positive energy to grow. Privately owned firms grow significantly at a lower rate than public firms, which contradicted our prior expectations. Recent empirical work by Amore et al. (2020) made a comparison between a family business and a non-family business firm's performance during the Covid-19 pandemic. They have found that the performance of family businesses during Covid-19 is better than that of non-family businesses. Even the outperformance of family business during the pandemic is more pronounced among companies led by family CEOs. Although private firms can have a possibility of having both family CEO or professional CEO, small firms like ours are more likely to own by family than professional CEOs. Under this assumption, a private firm owned by the family may perform better during a pandemic though it needs more deep analysis. Besides that, another possible explanation for our finding is it might be due to the case that most of the government interventions and industrial policy like protectionism and entry barriers benefit large state-owned firms and the private-owned firms might be constrained and disfavorable to grow in developing countries.

\section{The Dynamic Panel Data Analysis and Results}

The cross-sectional models indirectly assumed that the sources of all heterogeneity between firms are fully observed and reflected in the explanatory variables included in the regression. However, the correlation between the size of a firm and growth can also be the results of other unobserved firm-specific heterogeneities among firms in the specific economy. These unobserved factors might be associated with the initial size of the firm and other covariates in the regression; hence, the variation in growth between firms might be determined by these ignored factors, such as the skill of both entrepreneurs and/or workers, credit access, institutional or environmental factor in which firms interact. Consequently, the effects of the observed independent variables might be overestimated and the estimation may provide biased coefficients.

To address the above concern, a dynamic panel model is suggested in previous studies necessary. In such regression equations, the lagged dependent variable $\left(g_{i t-1}\right)$ is included as one regressor to control the endogeneity problem. 
Then, a dynamic regression model is stated as:

$$
g_{i t}=\alpha g_{i t-1}+\beta \ln X_{i t-1}+\delta^{\prime} Z+\gamma_{t}+\mu_{i}+\varepsilon_{i t}
$$

where $i$ represents firm and $t$ refers to the year, $Z$ is a matrix of independent variables, and $\gamma_{t}$ and $\mu_{i}$ are a time-specific and firm-specific time-invariant unobserved heterogeneity, respectively. The last term in Eq. (9), $\varepsilon_{i t}$ is the idiosyncratic random term with mean zero and variance $\sigma^{2} \varepsilon$.

Despite its growing importance, several statistical concerns are being raised (Greene 2018). The first concern here is that the lagged explanatory variable on the right-hand side of the equation might be associated with the disturbance term. Hence, pooled-OLS estimation for these time-series dimensions creates at least two key limitations: (1) it fails to account for the unobserved firm-specific (fixed) effects that will be included in the error term and (2) it fails to correct for potential endogeneity problems (Nickell 1981).

When the unobserved variation is fixed over time, the fixed effect (FE) approach can control and wipes out the unobserved time-invariant effects using the first difference to Eq. (9):

$$
\Delta g_{i t}=\alpha \Delta g_{i t-1}+\beta \Delta \ln X_{i t-1}+\delta^{\prime} \Delta Z+\Delta \varepsilon_{i t}
$$

However, using FE in the dynamic panel can also produce inconsistent parameters of interest because of the correlation between the differenced dependent variable and the error term(i.e., $\left.E\left(\Delta g_{i t}, \Delta \varepsilon_{i t}\right) \neq 0\right)$ ). To eliminate this econometric concern, instrumental variable regression which accounts for potential endogeneity problems is recommended. Hence, to provide adequate and more appropriate results of the GMM estimation, in which the lagged levels of the independent and dependent variables are used as an instrument is employed in this study (Arellano and Bond 1991). The GMM method can also correct important modeling anxieties, particularly unobserved heterogeneity and endogeneity of regressor while avoiding the dynamic panel bias (Nickell 1981). Moreover, it accommodates unbalanced panels and multiple endogenous variables (Canarella and Miller 2018).

However, the first difference GMM is also inappropriate as it has shortcomings to handle the weakness of its instruments which leads to bias and consistency of estimation results mainly coming from poor finite sample proportions. The lagged explanatory variables provide weak instruments (Blundell and Bond 1998). To mitigate the shortcoming, Blundell and Bond (1998) proposed a system GMM (SYS-GMM) estimation, where lagged first differences of the explanatory variables and dependent variable are used as instruments. Thus, deeper lags of the value of the dependent variable and endogenous explanatory variables are used as SYS-GMM instruments because very remote lags might not be informative enough in practice. Finally, the validity of the system GMM hinges on both the SarganHansen test of over-identification and the second-order autocorrelation test, in which their null hypotheses should not be rejected.

\subsection{Results of the Dynamic Panel Estimation}

In this section, following the methods outlined above and recent alternative specifications reported in Kiviet (2020) and Kripfganz (2019), various alternative specifications and sets of instruments are estimated and reported. All the possible alternative specifications as estimated by Stata package xtabond 2 are presented. 


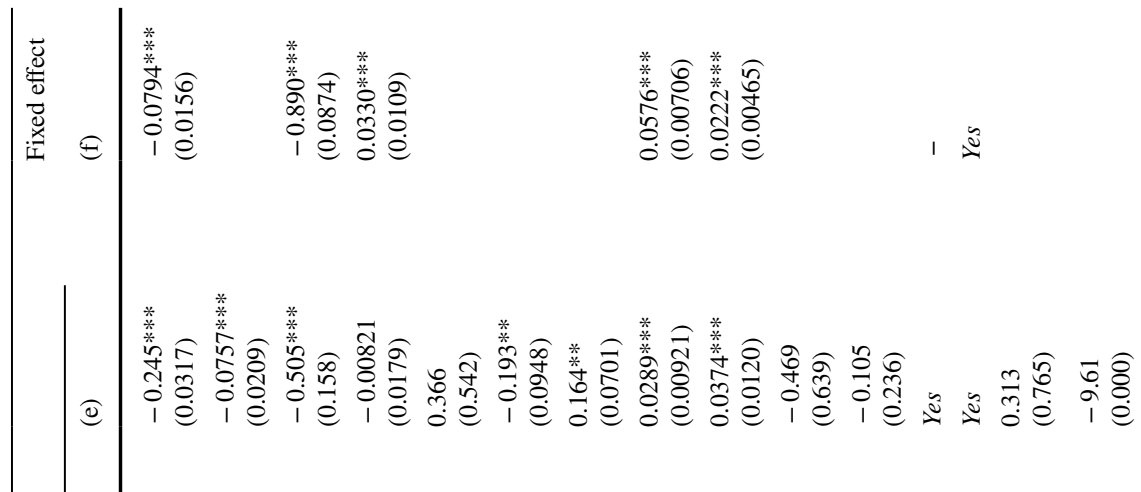

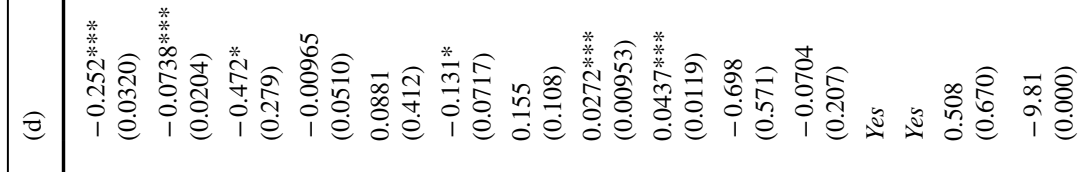

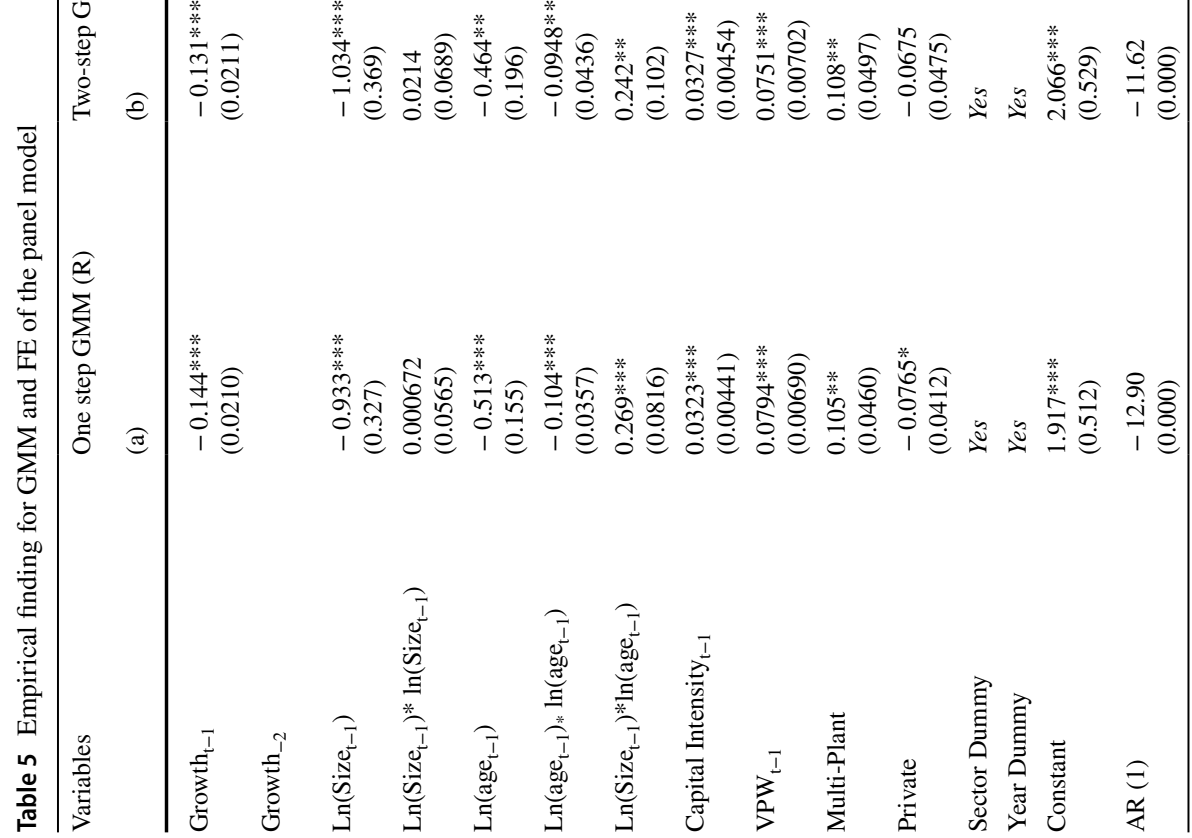

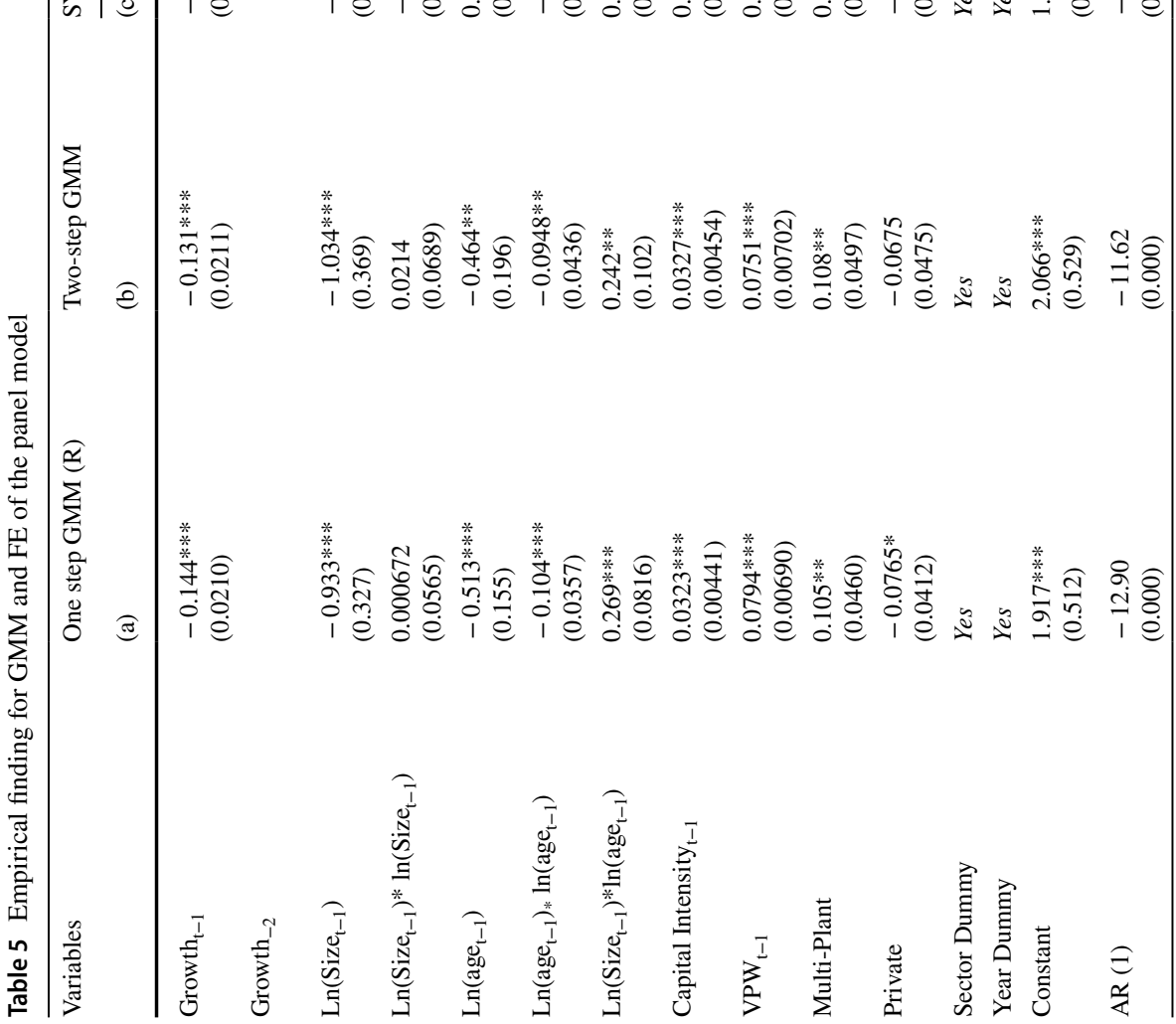




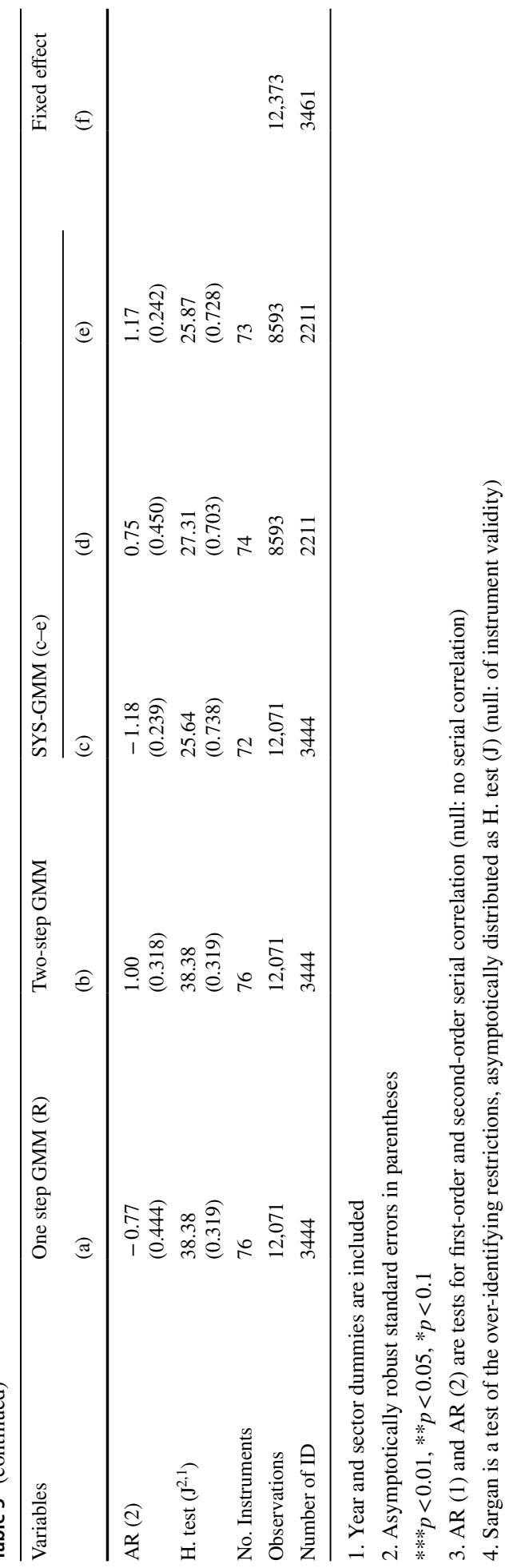


In Table 5 we have reported the estimates of these dynamic system GMM results. To compare the first two groups of regressions that include the lagged value of the dependent variable as a regressor and unrestricted lag structures, column (a) presents the one-step Arellano-Bond estimates with heteroscedasticity robust standard errors while column (b) reports the two-step GMM results with robust options. We estimated the two-step with a robust option but calculated the recently developed Wind Meijer-corrected standard errors. Some cross-sections are lost in creating lags and taking the first differences.

The specifications of the first two columns posit that all independent variables, except firm size, are presumed to be exogenous, even though none of the over-identifying restrictions following this assumption is exploited. Looking at columns (a) and (b) of Table 5, it is observed that the estimated coefficients associated with the two-step estimates do not differ much or sometimes slightly lower than those associated with the one-step GMM; however, the asymptotic standard errors of column (b) are similar or slightly larger. All the AR (2) test results in both columns show the absence of statistically reasonable second-order autocorrelation, which implies the lags of the variables are exogenous and, thus, instruments are valid and satisfied the required test statistics.

Similarly, the Sargan-Hansen test statistics, as calculated by xtabond2, found to be the same as in both columns (a) and (b) of Table 5 and are satisfactory but do not inspire great confidence. One possible justification is that they depend on strict homogeneity assumptions for the endogenous explanatory variables including the size indicators.

Columns (c-e) of Table 5 present the findings of the system GMM estimations of a different way to deal with the data we have. In this case, all explanatory variables except age, the dummy time-invariant variables, sector, and year are treated as endogenous and are internally instrumented. In column (c), two lags of the endogenous variable for the difference equation, two lags of the endogenous explanatory variable (firm size), and one lag for all the predetermined exogenous variables are considered relevant instruments.

Most standard errors in column (c) of Table 5 are slightly larger than in columns (a) and (b), as expected, but also reasonably most of the estimated coefficients vary among (c) and ( $\mathrm{a}$ and $\mathrm{b}$ ). In (c), size is negative but weakly significant at $10 \%$ whereas age changes its sign but it is statistically insignificant. The serial correlation tests of Arellano-Bond AR ( 1 and 2) for the autocorrelation tests are quite adequate, while the Hansen test is much more encouraging than before. In the model of column (c), we have found a higher value of Hansen tests for the 72 instruments included from each of the variables growth, size, and the lags of explanatory variables, $p$-values of $0.63,0.91$, and 0.64 , respectively. Hence, at first sight, it seems that we may have obtained statistically reasonable estimates.

In column (d) of Table 5, we have included the second lag of the dependent variable in the regression. The results regarding the coefficient of the lagged dependent variable are negative and statistically significant; size and age square are still negative but relatively weakly significant. Similarly, Table 5 of column (e) which estimates the same equation, using deeper lags of the dependent and the endogenous explanatory variables produced results comparable to those reported earlier. However, the overall Hansen test is improved and is much more comforting than earlier, and the $p$-values of AR (1) and AR (2) are still satisfactory. Thus, columns (c-e) of Table 5 can be considered the adequate accepted maintained statistical model, and our comparison and analysis are based on these estimates. The last model (column $\mathrm{f}$ ) is the estimated results of the fixed effect which is included to compare our result.

Turning to the estimated coefficients, the findings in Table 5 for the model in columns $(a-f)$ do not reject the dynamic nature of firm growth. Specifically, the estimated values on the lagged dependent variable are statistically significant at a higher level. That is, the 
higher growth of a particular year tends to lower growth rates next year. This evidence is of unique importance ${ }^{6}$ because earlier literature finds positive influences of the previous year's growth on current performance. This, in turn, suggests that firm growth in Ethiopia is not persistent, which conforms to the Penrose effect, since growing firms are less likely to achieve consecutive periods of growth in the subsequent period.

The patterns of negative growth remain valid when the second lags in the growth model are included in the regressions in columns (d) and (e). The signs and levels of significance of the estimated coefficients of the first and second lag remain quite similar, although considering longer lags did not yield significant results. Our evidence of negative persistence growth over time suggests a pattern of oscillating growth and it is in line with earlier studies (Coad et al. 2011; Canarella and Miller 2018; Dosi et al. 2019).

This suggests growth generates a negative "self-reinforcing" effect, meaning that firms that grow faster in 1 year may less likely to repeat the same performance in the subsequent year.

Our estimation result provides strong evidence that size takes a negative value and it is less than one in the models which pass the required statistical test (column c-e) which is strong evidence against Gibrat's law. Our finding shows that growth is associated with firm size and implies small firms grow faster. The negative effect of size on growth is in agreement with our aforementioned expectations and earlier works (Coad et al 2011).

To capture the nonlinear effects of size, we included size square in our estimation. The estimated coefficient on size square was found to be insignificant in all alternative specifications except in the fixed-effect model (column f). This indicates that there is no statically significant nonlinear correlation between size and growth in our case.

This is one of our key findings that show small firms grow faster, but as size increases, growth rate declines but firms may still survive with no significant growth. Interestingly it is in line with the arguments of Akcigit et al. (2016) indicating firms established by subsistence-seeking entrepreneurs with little insignificant growth potential, in the long run, might survive, while this might be partly due to that Ethiopia is a low-income country with a low level of urbanization and the consumption behavior of the society is most likely goods and services produced by those predominantly small firms, which indicates low levels of an absence of selection and the low rate of creative destruction might allow inefficient firms to survive. It is consistent with prior findings from underdeveloped economies (Akcigit et al. 2016 and Aydoğan 2020).

Age was found to be negative and significant in the first two models and positive but not significant in the last three models which pass the validity of the appropriate test statistics. Unlike the pooled OLS results, Age square was consistently found to be negative and statistically significant, suggesting growth decreases with age and the negative growth tends to be fast when firms get older and older which may be due to the commonly known inertia effect of old firms outweighing the expected learning effect obtained from experience. It can also be another evidence of lack of selection and presence of firms formed by subsistence-seeking entrepreneurs in the economy. Above all, labor productivity and capital intensity are found to have consistently positively and significantly affect the firm's growth in all the alternative specifications.

The ownership structure of firms at the center of manufacturing firm policies is an important factor for firm growth. For example, the Ethiopian manufacturing sector strategic document indicates the private sector as the engine of the manufacturing sector.

\footnotetext{
${ }^{6}$ This finding is contradicted with the findings of (Canarella and Miller 2018 and Coad 2007 among others).
} 
Surprisingly, firms owned by private individuals have negative growth in our data though it is not consistently significant in all alternative specifications. This is inconsistent with the findings of Amore et al. (2020) which shows family-owned Italian firms outperform better during the Covid-19 pandemic.

Finally, to capture the heterogeneity across sectors and time (year), we have estimated all the specifications from columns (a-e) with the sector and year dummies. The sector and year dummies were found to be significant in most cases, which supports the relevance of controlling sector and year dummies in our estimation.

To sum up, after managing the concerns of unobserved heterogeneity and endogeneity, the estimation results indicated a negative association of size and age on firm growth, which indicates smaller and younger firms grow fast: clear evidence against Gibrat's law. Our results found to be also partly in agreement with the findings of Tang (2015) that implies Gibrat's law is certain to be rejected ex-ante when a complete firm population in the economy is considered in the estimation.

\section{Conclusion}

In more recent panel data literature on the firm's growth, both theoretical and empirical, it has usually been taken for granted by a significant number of studies that Gibrat's law (1931) was fully valid, while many researchers have been labeled as "false " for a long time. Several theories stressed firm-level specifications as the main drivers of firms' growth whereas little attention has been paid to the methodological variations adopted by different studies and data employed. Contrary to that, this study adopts a multidimensional methodological approach to estimate the role of firm size, age, and other firm-specific determinants on firm growth. Hence, our study offers partial and, to some degree, rudimentary findings that mainly emanated from our inclusive methodological advantage implemented and the complete census-based dataset that covered 22 years and allowed the study to indicate clear and consistent evidence against Gibrat's law.

Both the empirical results for the classical dataset examined in the nonparametric estimation, and the empirical results obtained from the parametric setup evidenced that net growth tends to be higher for smaller firms compared to larger ones which are against Gibrat's law. However, the nonlinear connection between firm size and growth was found to be inconsistent among the methods we implemented and the specifications we estimated. Using the preferred nonparametric firm's classifications that earlier literature argues is more robust to such concerns, the results showed an inverse relationship between size and growth remained though it is not overwhelming when firm size is less than 20 workers and/ or age is older than 40 years.

Similarly, the study indicated that conditional on survival, younger firms grow fast, and hence once we control the firm size, the relationship between growth and age square disappeared and even reversed. The decline in growth is more pronounced for firms that have an age of more than 40 years. The strong negative effect of age and age squared on growth is unusual. This suggests that in a developing economy once firms are older the inertia effect outweighs the benefits obtained from learning by doing. It also shows once a new entrant has survived, those survived firms are growing fast though the growth rate fails to sustain as firms stay for a long period in the economy. This can be evidence of the absence of natural selection. 
Labor productivity and capital intensity were found to have a consistently positive and significant correlation with a firm's growth irrespective of the alternative specifications. Firms owned by private individuals are also observed to have negative growth though it is not consistently significant in all alternative specifications.

On the contrary, we found evidence of negative persistent growth overtime, since growing firms are found to be less likely to achieve growth in the subsequent period supporting the Penrose effect. This pattern of oscillating growth is uncommon in the developing economy's literature.

In terms of policy implications, our findings highlight the importance of smaller and younger firms on a firm's employment growth. Hence, policies and programs that promote both smaller and younger firms are likely to produce significant employment, which may play a significant role in reducing unemployment and enhancing firm growth. In a related manner, policymakers should target not only growth per se but also focus on building up firms' productivity, which helps to earn firm growth and employment in the economy.

The pattern of negative persistence growth also carries important policy implications. Though small and younger firms can grow faster, those firms that grow faster in some years may less likely sustain this achievement in the subsequent year. This indicates that policies that target sustainable employment growth need to address possible factors that create oscillations in the growth of firms. Thus, the persistence of this ability to grow in the coming year should be addressed.

In sum, as firms are persistently heterogeneous in the patterns of their growth, studies on the underlying determinants to create employment and firm size growth, where employment creation and industrialization are mostly needed in the developing economy, should be central to the efforts of the economics studies. Besides, alternative options including the balance sheets of those firms should be analyzed to find out any possible effects on firms to ensure persistent growth over time.

Author Contribution All authors have participated in the conception, analysis, and interpretation of results and approval of the final version.

\section{Declarations}

This manuscript has not been submitted to, nor is under review at, another journal or other publishing venue.

Conflict of Interest The authors declare that they have no conflicts of interest to declare that are relevant to the content of this article.

\section{References}

Akcigit U, Alp H, Peters M (2016) Lack of selection and limits to delegation: firm dynamics in developing countries [online] w21905. Cambridge: National Bureau of Economic Research

Amore MD, Pelucco V and Quarato F (2020) Family ownership during the Covid-19 pandemic [online] ID 3603991. SSRN Scholarly Paper. Rochester: Social Science Research Network

Angelini P, Generale A (2008) On the evolution of firm size distributions. Am Econ Rev 98(1):426-438

Arellano M, Bond S (1991) Some tests of specification for panel data: Monte Carlo evidence and an application to employment equations. Rev Econ Stud 58(2):277

Arouri H, Youssef AB, Quatraro F and Vivarelli M (2018) The determinants of young firms growth in Tunisia. 29 
Arrow K (1962) Economic welfare and the allocation of resources for invention [online] NBER Chapters. National Bureau of Economic Research, Inc

Axtell R (2001) U.S. Firm Sizes Are Zipf Distributed. Science 293(5536):1818-1820

Aydoğan Y (2020) Evolution Of the firm size distribution in Turkey. Öneri Dergisi 15(53):123-146

Aydogan Y, Donduran M (2019) Concluding Gibrat's law with Turkish firm data. Physica A Stat Mech Appl 533:122066

Ayyagari M, Demirguc-Kunt A and Maksimovic V (2011) Small vs. young firms across the world: contribution to employment, job creation, and growth [online] Policy Research Working Papers. The World Bank

Bigsten A, Gebreeyesus M (2007) The small, the young, and the productive: determinants of manufacturing firm growth in Ethiopia. Econ Dev Cult Change 55(4):813-840

Blundell R and Bond S (1998) 'Initial conditions and moment restrictions in dynamic panel data models'. J Econ 29

Cabral L, Mata J (2003) On the evolution of the firm size distribution: facts and theory. Am Econ Rev 93(4):1075-1090

Canarella G, Miller SM (2018) The determinants of growth in the U.S. Information and Communication Technology (ICT) industry: a firm-level analysis. Econ Model 70:259-271

Caves RE (1998) Industrial organization and new findings on the turnover and mobility of firms. J Econ Lit 36(4):1947-1982

Champonnois S (2008) What determines the distribution of firm sizes? 37

Clementi GL, Palazzo B (2016) Entry, exit, firm dynamics, and aggregate fluctuations. Am Econ J Macroecon 8(3): 1-41

Coad A (2007) Firm growth: a survey. Documents de travail du Centre d'Economie de la Sorbonne r07024. Université Panthéon-Sorbonne (Paris 1), Centre d'Economie de la Sorbonne

Coad A (2009) The growth of firms: a survey of theories and empirical evidence. New perspectives on the modern corporation. Cheltenham: Edward Elgar

Coad A (2018) Firm age: a survey. J Evol Econ 28(1):13-43

Coad A, Rao R, Tamagni F (2011) Growth processes of Italian manufacturing firms. Struct Chang Econ Dyn 22(1):54-70

Coad A, Daunfeldt S-O, Hozl W, Johansson D, Nightingale P (2014) High-growth firms: introduction to the special issue. Ind Corp Change 23:91-112

Coad A, Holm JR, Krafft J, Quatraro F (2018) Firm age and performance. J Evol Econ 28(1):1-11

Das S (1995) Size, age and firm growth in an infant industry: the computer hardware industry in India. Int J Ind Organ 13(1):111-126

Dosi G, Grazzi M, Moschella D, Pisano G and Tamagni F (2019) 'Long-term firm growth: an empirical analysis of US manufacturers 1959-2015'. Industrial and Corporate Change dtz044

Evans D (1987a) Tests of alternative theories of firm growth. J Polit Econ 95(4):657-674

Evans D (1987b) The relationship between firm growth, size, and age: estimates for 100 manufacturing industries. J Ind Econ 35(4):567-581

Geroski P, Gugler K (2004) Corporate growth convergence in Europe. Oxf Econ Pap 56(4):597-620

Geurts K, Van Biesebroeck J (2016) Firm creation and post-entry dynamics of de novo entrants. Int J Ind Organ 49:59-104

Gibrat R (1931) Les Inegalites economiques. Sirey, Paris

Goddard J, Wilson J, Blandon P (2002) Panel tests of Gibrat's law for Japanese manufacturing. Int J Ind Organ 20(3):415-433

Greene WH (2018) Econometric Analysis 8th Edu

Haltiwanger J, Jarmin RS, Miranda J (2013) Who creates jobs? Small versus large versus young. Rev Econ Stat 95(2):347-361

Hannan MT, Freeman J (1984) Structural inertia and organizational change. Am Sociol Rev 49(2):149

Hart PE, Oulton N (1996) Growth and size of firms. Econ J 106(438):1242-1252

Hart PE, Prais SJ (1956) The analysis of business concentration: a statistical approach. J Royal Stat Soc Series A (General) 119(2):150-191

Headd B, Kirchhoff B (2009) The growth, decline, and survival of small businesses: an exploratory study of life cycles*. J Small Bus Manage 47(4):531-550

Jovanovic B (1982) Selection and the evolution of industry. Econometrica 50(3):649-670

Kiviet JF (2020) Microeconometric dynamic panel data methods: model specification and selection issues. Econ Stat 13:16-45

Kripfganz S (2019) Generalized method of moments estimation of linear dynamic panel data models. 128

Nichter S, Goldmark L (2009) Small firm growth in developing countries. World Dev 37(9):1453-1464

Nickell S (1981) Biases in dynamic models with fixed effects. Econometrica 49(6):1417-1426 
Oqubay A (2019) 'The structure and performance of the Ethiopian manufacturing sector'. in The Oxford Handbook of the Ethiopian Economy Oqubay, A. Oxford University Press, 629-650

Simon HA, Bonini CP (1958) The size distribution of business firms. Am Econ Rev 48(4):607-617

Sleuwaegen L, Goedhuys M (2002) Growth of firms in developing countries, evidence from Cote d'Ivoire. J Dev Econ 68(1):117-135

Söderbom M (2012) Firm size and structural change: a case study of Ethiopia. J Afr Econ 21(suppl_2):ii126-ii151

Sutton J (1997) Gibrat's Legacy. J Econ Lit 35(1):40-59

Tang A (2015) Does Gibrat's law hold for Swedish energy firms? Empir Econ 49(2):659-674

Teal F (2016) Firm size, employment and value-added in African manufacturing firms: why Ghana needs its 1 percent. 16

Publisher's Note Springer Nature remains neutral with regard to jurisdictional claims in published maps and institutional affiliations. 